\title{
Article
}

\section{PREP2 Algorithm Predictions Are Correct at 2 Years Poststroke for Most Patients}

Smith, Marie-Claire, Ackerley, Suzanne, Barber, P. Alan, Byblow, Winston D. and Stinear, Cathy M.

Available at http://clok.uclan.ac.uk/34859/

Smith, Marie-Claire, Ackerley, Suzanne ORCID: 0000-0002-7059-3329, Barber, P. Alan, Byblow, Winston D. and Stinear, Cathy M. (2019) PREP2 Algorithm Predictions Are Correct at 2 Years Poststroke for Most Patients.

Neurorehabilitation and Neural Repair, 33 (9). pp. 635-642. ISSN 1545-9683

It is advisable to refer to the publisher's version if you intend to cite from the work. http://dx.doi.org/10.1177/1545968319860481

For more information about UCLan's research in this area go to

http://www.uclan.ac.uk/researchgroups/ and search for <name of research Group>.

For information about Research generally at UCLan please go to http://www.uclan.ac.uk/research/

All outputs in CLoK are protected by Intellectual Property Rights law, including Copyright law. Copyright, IPR and Moral Rights for the works on this site are retained by the individual authors and/or other copyright owners. Terms and conditions for use of this material are defined in the policies page. 


\section{PREP2 algorithm predictions are correct at 2 years post-stroke for most patients}

Marie-Claire Smith PhD, ${ }^{* 1,2}$ Suzanne J Ackerley PhD, ${ }^{* 1,2} \mathrm{P}$ Alan Barber FRACP, ${ }^{1,2,3}$ Winston

D Byblow $\mathrm{PhD},{ }^{2,4}$ Cathy M Stinear $\mathrm{PhD}^{1,2}$

${ }^{*}$ Contributed equally to this work

1. Department of Medicine, University of Auckland, Auckland, New Zealand

2. Centre for Brain Research, University of Auckland, Auckland, New Zealand

3. Neurology, Auckland District Health Board, Auckland, New Zealand

4. Department of Exercise Sciences, University of Auckland, Auckland, New Zealand

Corresponding author:

Cathy Stinear

Department of Medicine

University of Auckland

Private Bag 92019

Auckland 1142

New Zealand

c.stinear@auckland.ac.nz

+6499233779

Tables: 3

Figures: 3

Word count: 4,400 


\section{Abstract}

\section{Background}

The PREP2 algorithm combines clinical and neurophysiological measures to predict upperlimb (UL) motor outcomes 3 months post-stroke, using four prediction categories based on Action Research Arm Test (ARAT) scores. The algorithm was accurate at 3 months for $75 \%$ of participants in a previous validation study.

\section{Objective}

This study aimed to evaluate whether PREP2 predictions made at baseline are correct 2 years post-stroke. We also assessed whether patients' UL performance remained stable, improved or worsened between 3 months and 2 years after stroke.

\section{Methods}

This is a follow-up study of 192 participants recruited and assessed in the original PREP2 validation study. Participants who completed assessments 3 months post-stroke $(n=157)$ were invited to complete follow-up assessments at 2 years post-stroke for the present study. UL outcomes were assessed with the ARAT, upper extremity Fugl-Meyer scale (FM-UE), and Motor Activity Log (MAL).

\section{Results}

Eighty-six participants completed 2-year follow-up assessments in this study. PREP2 predictions made at baseline were correct for $69 / 86$ (80\%) of participants 2 years poststroke, and PREP2 UL outcome category was stable between 3 months and 2 years poststroke for $71 / 86(83 \%)$. There was no difference in age, stroke severity or comorbidities between patients whose category remained stable, improved or deteriorated.

\section{Conclusions}

PREP2 algorithm predictions made within days of stroke are correct at both 3 months and 2 years post-stroke for most patients. Further investigation may be useful to identify which patients are likely to improve, remain stable or deteriorate between 3 months and 2 years. Keywords: Upper limb; Motor; Prognosis; Outcome; Biomarkers; Stroke; Rehabilitation 


\section{Introduction}

Recovery of upper-limb (UL) function after stroke is important for regaining independence in activities of daily living. ${ }^{1}$ Early prediction of UL outcome may increase rehabilitation efficiency by tailoring therapy for individual patients. ${ }^{2}$ However, making accurate predictions for individual patients based on clinical measures alone can be difficult. ${ }^{3}$

The PREP2 algorithm combines clinical and neurophysiological measures within a few days of stroke to make predictions for UL functional outcomes at 3 months post-stroke (www.presto.auckland.ac.nz). ${ }^{4}$ Patients are predicted to achieve one of four functional UL outcome categories: Excellent, Good, Limited or Poor. These UL functional outcome categories are based on ranges of scores on the Action Research Arm test (ARAT), which were previously established through hypothesis free cluster analysis ${ }^{5}$ and subsequently refined (Table 1). ${ }^{4}$ Information that can be offered to patients in each predicted outcome category is provided in Table 1. This includes the expected level of UL function by 3 months post-stroke, and a suggested rehabilitation focus.

The PREP2 algorithm starts by grading paretic UL shoulder abduction and finger extension (SAFE) strength at day 3 post-stroke using the Medical Research Council grades (Figure 1). If the sum of these grades is $\geq 5 / 10$, the patient's age $(<80$ or $\geq 80)$ is taken into account to predict either an Excellent or Good UL functional outcome at 3 months. For patients with a SAFE score $<5$, ipsilesional corticospinal system function is evaluated with transcranial magnetic stimulation (TMS). Patients with motor evoked potentials $(M E P+)$ in the first dorsal interosseus (FDI) or extensor carpi radialis (ECR) muscles of the paretic UL are predicted to achieve a Good UL functional outcome, regardless of the initial motor impairment. Patients without MEPs (MEP-) are predicted to achieve a Limited or Poor functional UL outcome, depending on overall stroke severity measured at day 3 post-stroke with the National 
Institute of Health Stroke Scale (NIHSS). At 3 months post-stroke PREP2 predictions are correct for $75 \%$ of patients, with predictions too optimistic for most of the remaining $25 \% .{ }^{4}$

Most motor recovery after stroke occurs within the first 3 months. ${ }^{6-12}$ However, a plateau in motor performance might not occur until 5 to 6 months post-stroke for some patients with more severe initial impairment. ${ }^{13,14}$ To the best of our knowledge, no longitudinal studies have tracked UL performance from early after stroke for more than 6 months. This means little is known about what happens to UL impairment, function, and use once a patient reaches plateau and moves into the early chronic phase of stroke. Learned non-use may contribute to deterioration in UL motor function from the peak motor performance achieved at plateau, particularly for patients with more severe UL impairment. ${ }^{14,15}$ This could make it difficult to discern whether the benefits of UL therapy reported in studies with patients at the chronic stage are due to improvements over and above participants' previous maximal function, or due to participants being boosted back up to their previous best after deterioration since the sub-acute stage.

The aim of this study was to determine whether PREP2 predictions made within a few days post-stroke were correct 2 years after stroke, and determine whether UL performance improves, deteriorates or remains stable between 3 months and 2 years after stroke. We hypothesised that PREP2 predictions made at baseline would be correct at 2 years poststroke, and PREP2 outcome category and UL motor performance would remain stable between 3 months and 2 years after stroke.

\section{Methods}

This is a follow-up study of the 192 patients recruited within 3 days of stroke to participate in the PREP2 algorithm validation study, which was previously reported. ${ }^{2}$ Patients were eligible for participation in the PREP2 validation study if they were aged at least 18 years, and had 
experienced an ischemic stroke or intracerebral hemorrhage producing unilateral UL weakness within the previous 72 hours. Previous stroke and acute reperfusion therapies were allowed. Patients were excluded if they had cerebellar stroke, cognitive or communication impairments precluding informed consent, or if they lived out of the study area precluding follow-up. The PREP2 algorithm (Figure 1) was used to predict UL functional outcome within days of stroke for all participants in the validation study. ${ }^{4}$

Of the original 192 participants in the PREP2 validation study, 157 (82\%) completed followup assessments at 3 months post-stroke. At 2 years post stroke, attempts were made to contact all participants who had completed 3 month assessments in the PREP2 validation study ( $n=157$ ) to determine eligibility for participation in the present 2 year follow-up study. All 157 participants were considered eligible unless they had moved out of the study area (not available for in person assessments), they were unable to be contacted, or their medical status, cognition or communication had declined to the point that they were no longer able to provide informed consent or were too unwell to participate. The 2 year time point was chosen to maximise the time since stroke while minimising the expected natural attrition over time as patients experience medical deterioration or death. ${ }^{16}$ The study was approved by the regional ethics committee and written informed consent was obtained from each participant.

Follow-up assessments at 2 years post-stroke were completed by trained clinical assessors who were blinded to the participants' original PREP2 prediction. The assessments included: Action Research Arm Test (ARAT) to determine PREP2 outcome category at 2 years; upper extremity Fugl-Meyer Assessment (FM-UE) to measure motor impairment; and the Motor Activity Log (MAL) for self-reported use of the paretic UL. Baseline clinical and demographic data, baseline PREP2 prediction, 3 month PREP2 outcome category, and 3 month FM-UE, ARAT and MAL scores for each participant were retrieved from the PREP2 validation study dataset. 
Non-parametric tests were used for analyses due to the non-normal distributions of data. Pearson Chi-Square tests were used to compare categorical baseline characteristics of participants included in this study $(n=86)$ with those who were not available for follow-up at 2 years $(n=71)$. The percentage of patients in this follow-up study who achieved their predicted UL outcome at 2 years was calculated. The percentage of patients that changed PREP2 outcome category between 3 months and 2 years post-stroke was also calculated separately for patients whose category improved or worsened. Clinical scores (ARAT, FMUE, MAL) were compared between 3 months and 2 years post-stroke using related-samples Wilcoxon signed rank tests. Differences of 6 points in the FM-UE and ARAT scores were considered clinically meaningful. ${ }^{17,18}$ All tests were two-sided with alpha $=0.05$ and are reported with $95 \%$ confidence intervals.

\section{Results}

Of the 157 PREP2 validation study patients who completed a 3 month post-stroke assessment, 86 participated in the present follow-up study at 2 years post-stroke (33 (38\%) women, mean (SD) age 72 (13) y) (Figure 2, Table 2). These 86 participants had a lower median age, a lower incidence of atrial fibrillation, fewer comorbidities, and a lower proportion of women compared to the 71 patients who were not available for follow-up at 2 years (Table 2). The reasons for being unavailable for follow up assessment at 2 years are reported in Figure 2: deceased (19), unable to be contacted (19), medically unwell (8), cognitive deterioration (3), moved out of the study area (9), and declined to participate (13).

PREP2 predictions made at baseline were correct for $69 / 86$ participants (80\%) 2 years poststroke (Table 3). Of the remaining 17 participants, PREP2 category was better than predicted for $9(11 \%)$ and worse than predicted for $8(9 \%)$ participants at 2 years poststroke. 
Most participants $(71 / 86,83 \%)$ remained in the same PREP2 UL outcome category between 3 months and 2 years post-stroke. Of the 15 participants who changed category, 10 improved, 5 deteriorated, and all were predicted to achieve either a Good or Excellent UL outcome (Figure 3). Six of the 10 participants who improved had not achieved their predicted Excellent outcome category by 3 months, but achieved it by 2 years. Two of the 10 participants who improved had achieved their predicted Good outcome by 3 months, but exceeded their prediction, achieving an Excellent UL outcome by 2 years. The remaining two participants who improved had been predicted to achieve a Good outcome by 3 months, but had only achieved a Limited outcome by this time. Between 3 months and 2 years, one of these participants improved to achieve their predicted Good outcome, and the other exceeded their predicted Good outcome to achieve an Excellent outcome. None of the participants predicted to achieve a Limited or Poor outcome changed categories between 3 months and 2 years post-stroke. There were no differences in age, stroke severity, or comorbidities between participants whose UL outcome category remained stable, improved or worsened (all $p>0.1$ ).

ARAT, FM-UE, and MAL scores could change between 3 months and 2 years without resulting in a change in PREP2 outcome category. Therefore, the differences in these UL scores between 3 months and 2 years were also examined. At the group level, the median difference between ARAT scores at 3 months and 2 years was 1 point $(95 \% \mathrm{Cl} 0-1.5, \mathrm{p}=$ 0.012), and for FM-UE scores was 1.5 points $(95 \% \mathrm{Cl} 0.5-2.5, \mathrm{p}=0.005)$. These differences are statistically significant but not clinically meaningful ${ }^{6,7}$ (Table 3). However, some individual participants exhibited clinically meaningful increases and decreases in ARAT $(n=13,15 \%)$ and FM-UE $(n=26,30 \%)$ scores (Table 3$)$, without necessarily changing outcome category. Of the 18 (21\%) participants who increased FM scores by 6 points or more, 6 participants also exhibited clinically meaningful increases in ARAT score, and 5 of these improved PREP2 outcome category. Four of the 8 participants who decreased FM score also decreased ARAT score and dropped to a lower PREP2 UL 
outcome category. Three participants (3\%) meaningfully improved ARAT score without a corresponding increase in FM score. The median difference between MAL scores at 3 months and 2 years was $0.1(-0.03-0.4)$, which was neither statistically nor clinically significant.

\section{Discussion}

PREP2 algorithm predictions about UL functional outcome made within days of stroke are correct for $80 \%$ of patients at 2 years post-stroke. Most participants (83\%) remained in the same PREP2 category between 3 months and 2 years, and median scores for motor function (ARAT), motor impairment (FM-UE), and use of the paretic hand and arm (MAL) did not meaningfully change between these time points. These results indicate that functional limitations seen in patients at the chronic stage are predictable and likely to have been fairly stable since 3 months post-stroke. Of the ten participants whose UL outcome category improved between 3 months and 2 years, only three exceeded their original prediction, while the remaining seven took longer than 3 months to achieve their original predicted UL function, achieving this by 2 years post-stroke. Five participants deteriorated to a lower category between 3 months and 2 years. None of the participants predicted to achieve a Limited or Poor outcome changed categories between 3 months and 2 years post-stroke. There was no difference in age, stroke severity or comorbidities between those whose category remained stable, improved or deteriorated. Further investigation would be useful to identify factors that predict which patients take longer than 3 months to achieve their predicted UL function and which patients are at risk of deteriorating after 3 months.

While median ARAT and FM-UE scores did not meaningfully change between 3 months and 2 years after stroke for this group of participants, some individuals did exhibit a meaningful increase or decrease in these scores. However, only a third of the 18 participants who experienced a meaningful increase in FM-UE scores also experienced a meaningful 
increase in UL hand and arm function (ARAT score), and only half of those who decreased FM scores $(n=8)$ also decreased ARAT score. Despite a clinically meaningful change in UL function on the ARAT score for these participants, self-reported use of the UL did not change. This reflects the high threshold required for patients to translate changes in UL impairment into UL function and use of the UL in daily life. ${ }^{21}$

Spontaneous biological recovery processes drive improvements in motor control and impairment during the initial weeks after stroke with most motor recovery occurring within the first 3 months post-stroke. ${ }^{6-11}$ However studies at the chronic stage also report improvements in UL function after therapeutic interventions. The findings of this study shed some light on whether these improvements at the chronic stage are over and above previous best performance or whether the benefit from UL therapy at the chronic stage is due to reconditioning, or boosting the patients back up to previous best function. Although ARAT score meaningfully increased for $9(10 \%)$ and decreased for $4(5 \%)$ participants between 3 months and 2 years post-stroke, overall UL performance (UL impairment, function and selfreported use) remained fairly stable during this time for the majority of participants. This stability in UL performance between 3 months and 2 years post-stroke suggests that improvements at the group level, reported after an intervention at the chronic stage, are likely to be true improvements over and above previous performance. At the chronic stage, improvements in motor performance may be achieved by learning to compensate for residual impairments, as motor learning is unimpaired after stroke. ${ }^{19,20}$

Of the 157 PREP2 validation study participants assessed at 3 months, only 86 (55\%) were available to participate in this follow-up study 2 years after stroke. These participants were younger, had a lower proportion of women, and had fewer co-morbidities, compared to those who were unavailable. Stroke type, location and severity did not distinguish between patients available for follow-up and those who were unavailable. The unavailability of nearly half of the PREP2 validation study participants limited the sample size for this follow-up study. 
However, this was largely unavoidable, as most were unavailable due to illness, death, or moving out of the study area. This attrition rate is similar to other longitudinal studies poststroke. ${ }^{16}$ Other limitations of this study include a lack of measures between 3 months and 2 years post-stroke, and no record of any UL rehabilitation undertaken in this time.

In conclusion, using the PREP2 algorithm, it is possible to predict UL functional outcomes within a few days of stroke, and these predictions are correct for most patients at both 3 months and 2 years. Most UL motor recovery occurs within the first 3 months after stroke, therefore 3 months is an appropriate time point for UL predictions. Further investigation may be useful to improve the overall accuracy of the algorithm and identify which patients are likely to improve, remain stable or deteriorate between 3 months and 2 years.

\section{Acknowledgements}

We thank Christine Mangold, Alison Elston, and Jenelle Preece for assistance with data collection. We thank the Neurological Foundation of New Zealand, Health Research Council of New Zealand, and the Julius Brendel Trust, for funding support.

\section{Disclosures}

None. 


\section{References}

1. Veerbeek JM, Kwakkel G, van Wegen EE, Ket JC, Heymans MW. Early prediction of outcome of activities of daily living after stroke: a systematic review. Stroke. $2011 ; 42(5): 1482-1488$

2. Stinear CM, Byblow WD, Ackerley SJ, Barber PA, Smith MC. Predicting Recovery Potential for Individual Stroke Patients Increases Rehabilitation Efficiency. Stroke. 2017;48(4):1011-1019.

3. Nijland $\mathrm{RH}$, van Wegen EE, Harmeling-van der Wel BC, Kwakkel G, Early Prediction of Functional Outcome After Stroke I. Accuracy of physical therapists' early predictions of upper-limb function in hospital stroke units: the EPOS Study. Phys Ther. 2013;93(4):460-469.

4. Stinear CM, Byblow WD, Ackerley SJ, Smith MC, Borges VM, Barber PA. PREP2: A biomarker-based algorithm for predicting upper limb function after stroke. Ann Clin Trans/ Neurol. 2017;4(11):811-820.

5. Stinear CM, Barber PA, Petoe M, Anwar S, Byblow WD. The PREP algorithm predicts potential for upper limb recovery after stroke. Brain. 2012;135(Pt 8):25272535.

6. Zeiler SR, Krakauer JW. The interaction between training and plasticity in the poststroke brain. Curr Opin Neurol. 2013;26(6):609-616.

7. Byblow WD, Stinear CM, Barber PA, Petoe MA, Ackerley SJ. Proportional recovery after stroke depends on corticomotor integrity. Ann Neurol. 2015;78(6):848-859.

8. Prabhakaran S, Zarahn E, Riley C, et al. Inter-individual variability in the capacity for motor recovery after ischemic stroke. Neurorehabil Neural Repair. 2008;22(1):64-71.

9. Smith MC, Byblow WD, Barber PA, Stinear CM. Proportional Recovery From Lower Limb Motor Impairment After Stroke. Stroke. 2017;48(5):1400-1403.

10. Xu J, Ejaz N, Hertler B, et al. Separable systems for recovery of finger strength and control after stroke. J Neurophysiol. 2017:118(2):1151-1163 
11. Cortes JC, Goldsmith J, Harran MD, et al. A Short and Distinct Time Window for Recovery of Arm Motor Control Early After Stroke Revealed With a Global Measure of Trajectory Kinematics. Neurorehabil Neural Repair. 2017;31(6):552-560.

12. Verheyden G, Nieuwboer A, De Wit L, et al. Time course of trunk, arm, leg, and functional recovery after ischemic stroke. Neurorehabil Neural Repair. 2008;22(2):173-179.

13. Jorgensen HS, Nakayama H, Raaschou HO, Vive-Larsen J, Stoier M, Olsen TS. Outcome and time course of recovery in stroke. Part II: Time course of recovery. The Copenhagen Stroke Study. Arch Phys Med Rehabil. 1995;76(5):406-412.

14. Stinear CM, Byblow WD. Predicting and accelerating motor recovery after stroke. Curr Opin Neurol. 2014;27(6):624-630.

15. Kwakkel G, Veerbeek JM, van Wegen EE, Wolf SL. Constraint-induced movement therapy after stroke. Lancet Neurol. 2015;14(2):224-234.

16. Ganesh A, Luengo-Fernandez R, Wharton RM, et al. Time Course of Evolution of Disability and Cause-Specific Mortality After Ischemic Stroke: Implications for Trial Design. J Am Heart Assoc. 2017;6(6).

17. Page SJ, Fulk GD, Boyne P. Clinically important differences for the upper-extremity fugl-meyer scale in people with minimal to moderate impairment due to chronic stroke. Phys Ther. 2012;92(6):791-798.

18. Van der Lee JH, De Groot V, Beckerman H, Wagenaar RC, Lankhorst GJ, Bouter LM. The intra- and interrater reliability of the action research arm test: a practical test of upper extremity function in patients with stroke. Arch Phys Med Rehabil. $2001 ; 82(1): 14-19$.

19. Hardwick RM, Rajan VA, Bastian AJ, Krakauer JW, Celnik PA. Motor Learning in Stroke: Trained Patients Are Not Equal to Untrained Patients With Less Impairment. Neurorehabil Neural Repair. 2017;31(2):178-189. 
20. Kitago T, Goldsmith J, Harran M, et al. Robotic therapy for chronic stroke: general recovery of impairment or improved task-specific skill? J Neurophysiol. $2015 ; 114(3): 1885-1894$.

21. Stinear CM, Byblow WD. Letter by Stinear and Byblow regarding article, "patientreported measures provide unique insights into motor function after stroke". Stroke. 2013;44(7):e79. 


\section{Figure legends}

Figure 1. The PREP2 algorithm. SAFE = Shoulder Abduction, Finger Extension score, which is the sum of the Medical Research Council grades for each of these movements, out of 5 , for a total SAFE score out of 10. MEP $+=$ Motor Evoked Potentials can be elicited from the paretic extensor carpi radialis (ECR) and/or first dorsal interosseous (FDI) muscles of the paretic UL using transcranial magnetic stimulation. NIHSS = National Institutes of Health Stroke Scale. The algorithm predicts one of four possible upper limb functional outcomes at 3 months post-stroke. Each prediction category is associated with rehabilitation goals that can be used to tailor upper limb therapy. ${ }^{2}$ The coloured dots represent, proportionally, PREP2 algorithm accuracy. The dots are colour coded based on the outcome category actually achieved 3 months post-stroke (Green = Excellent, Blue = Good, Orange = Limited, Red $=$ Poor $)$.

Figure 2: Study flowchart.

Figure 3: Fifteen participants changed PREP2 category between 3 months and 2 years, based on Action Research Arm Test (ARAT) score (max = 57). The 71 participants who did not change category are not depicted. Each dot represents a participant and is colour coded based on their original PREP2 prediction (Green $=$ Excellent, Blue $=$ Good). The coloured zone indicates the PREP2 outcome category actually achieved. Dots that do not match the colour of their zone indicates the participant either under or over-achieved their prediction at that time point. For example, six participants predicted to achieve an Excellent UL outcome (green dot) by 3 months only achieved a Good UL outcome (blue zone) at this time point. They improved to achieve their Excellent UL outcome by 2 years. 
Table 1. PREP2 prediction category description and suggested rehabilitation focus

\begin{tabular}{|c|c|c|c|}
\hline $\begin{array}{l}\text { Predicted } \\
\text { Outcome }\end{array}$ & $\begin{array}{l}\text { ARAT score } \\
\text { (out of } 57 \text { ) }\end{array}$ & Category description & Rehabilitation focus \\
\hline Excellent & $50-57$ & $\begin{array}{l}\text { Potential to use the hand and arm } \\
\text { fairly normally for most activities of } \\
\text { daily living within three months }\end{array}$ & $\begin{array}{l}\text { Promote normal function of the } \\
\text { affected hand and arm by } \\
\text { improving strength, } \\
\text { coordination, and fine motor } \\
\text { control. Minimise compensation } \\
\text { with the other hand and arm, } \\
\text { and the trunk. }\end{array}$ \\
\hline Good & $34-48$ & $\begin{array}{l}\text { Potential to be using the affected } \\
\text { hand and arm for most activities of } \\
\text { daily living within three months, } \\
\text { though with some weakness, } \\
\text { slowness, or clumsiness }\end{array}$ & $\begin{array}{l}\text { Promote normal function of the } \\
\text { affected hand and arm by } \\
\text { improving strength, } \\
\text { coordination. Minimise } \\
\text { compensation with the other } \\
\text { hand and arm, and the trunk. }\end{array}$ \\
\hline Limited & $13-31$ & $\begin{array}{l}\text { Potential to regain some } \\
\text { movement in the affected hand } \\
\text { and arm within three months, but } \\
\text { daily activities are likely to require } \\
\text { significant modification. Unlikely to } \\
\text { regain dextrous hand function. }\end{array}$ & $\begin{array}{l}\text { Improve strength and active } \\
\text { range of motion. Promote } \\
\text { adaptation in daily activities, } \\
\text { incorporating the affected upper } \\
\text { limb wherever safely possible. }\end{array}$ \\
\hline Poor & $0-9$ & $\begin{array}{l}\text { Unlikely to regain useful hand and } \\
\text { arm function within three months. } \\
\text { May be able to use the affected } \\
\text { hand and arm as a stabiliser in } \\
\text { bimanual tasks. }\end{array}$ & $\begin{array}{l}\text { Prevent secondary } \\
\text { complications such as pain, } \\
\text { spasticity and shoulder } \\
\text { instability. Reduce disability by } \\
\text { learning to complete daily } \\
\text { activities with the stronger hand } \\
\text { and arm. }\end{array}$ \\
\hline
\end{tabular}


Table 2. Baseline data obtained within 7 days post-stroke.

\begin{tabular}{|c|c|c|c|c|}
\hline & $\begin{array}{l}\text { Full sample } \\
\text { at } 3 \mathrm{~m} \\
(\mathrm{n}=157) \\
\end{array}$ & $\begin{array}{l}\text { Not assessed } \\
\text { at } 2 \mathrm{y} \\
(\mathrm{n}=71)\end{array}$ & $\begin{array}{l}\text { Assessed } \\
\text { at } 2 \text { y } \\
(n=86) \\
\end{array}$ & $p$-value \\
\hline \multicolumn{5}{|l|}{ Demographic characteristics } \\
\hline \multicolumn{5}{|l|}{ Age, y } \\
\hline Median (range) & $74(18-98)$ & $78(18-98)$ & $72(38-93)$ & 0.024 \\
\hline \multicolumn{5}{|l|}{ Sex } \\
\hline Female & $73(46 \%)$ & $40(56 \%)$ & $33(38 \%)$ & 0.025 \\
\hline \multicolumn{5}{|l|}{ Stroke risk factors } \\
\hline Smoker & $14(9 \%)$ & $8(11 \%)$ & $6(7 \%)$ & 0.62 \\
\hline Ex-smoker & $28(18 \%)$ & $13(18 \%)$ & $15(17 \%)$ & 0.62 \\
\hline Diabetes mellitus & $36(23 \%)$ & $19(27 \%)$ & $17(20 \%)$ & 0.30 \\
\hline Hypertension & $101(64 \%)$ & $47(66 \%)$ & $54(63 \%)$ & 0.66 \\
\hline Dyslipidemia & $49(31 \%)$ & $23(32 \%)$ & $26(30 \%)$ & 0.77 \\
\hline Atrial fibrillation & $40(25 \%)$ & $24(34 \%)$ & $16(19 \%)$ & 0.03 \\
\hline Previous cardiac history & $49(31 \%)$ & $26(37 \%)$ & $23(27 \%)$ & 0.18 \\
\hline Comorbidities & & & & 0.001 \\
\hline Low (Charlson < 2) & $109(69 \%)$ & $40(56 \%)$ & $69(80 \%)$ & \\
\hline High (Charlson $\geq 2$ ) & $48(31 \%)$ & $31(44 \%)$ & $17(20 \%)$ & \\
\hline \multicolumn{5}{|l|}{ Stroke characteristics } \\
\hline First stroke & $131(83 \%)$ & $56(79 \%)$ & $75(87 \%)$ & 0.16 \\
\hline Stroke type & & & & 0.65 \\
\hline Total anterior circulation infarct & $11(7 \%)$ & $5(7 \%)$ & $6(7 \%)$ & \\
\hline Partial anterior circulation infarct & $65(41 \%)$ & $34(48 \%)$ & $31(36 \%)$ & \\
\hline Lacunar infarct & $51(32 \%)$ & $20(28 \%)$ & $31(36 \%)$ & \\
\hline $\begin{array}{l}\text { Posterior circulation infarct } \\
\text { (excluding cerebellar) }\end{array}$ & $9(6 \%)$ & $4(6 \%)$ & $5(6 \%)$ & \\
\hline Intracerebral hemorrhage & $21(13 \%)$ & $8(11 \%)$ & $13(15 \%)$ & \\
\hline \multicolumn{5}{|l|}{ Hemisphere } \\
\hline Right & $77(49 \%)$ & $39(55 \%)$ & $38(44 \%)$ & 0.18 \\
\hline \multicolumn{5}{|l|}{ Thrombolysis } \\
\hline Yes & $17(11 \%)$ & $8(11 \%)$ & $9(11 \%)$ & 0.87 \\
\hline \multicolumn{5}{|l|}{ Clot retrieval } \\
\hline Yes & $2(1 \%)$ & $1(1 \%)$ & $1(1 \%)$ & 1.00 \\
\hline \multicolumn{5}{|l|}{ Stroke severity } \\
\hline NIHSS median (range) & $4(0-19)$ & $4(0-17)$ & $4(0-19)$ & 0.74 \\
\hline \multicolumn{5}{|l|}{ Motor impairment } \\
\hline FM-UE median (range) & $52(2-65)$ & $49(4-65)$ & $52(2-65)$ & 0.87 \\
\hline SAFE $\geq 5$ & $111(71 \%)$ & $48(68 \%)$ & $63(73 \%)$ & 0.44 \\
\hline SAFE $<5$ & $46(29 \%)$ & $23(32 \%)$ & $23(27 \%)$ & \\
\hline MEPs present & $134(85 \%)$ & $57(80 \%)$ & $77(90 \%)$ & 0.10 \\
\hline PREP2 prediction & & & & 0.32 \\
\hline Excellent & $98(63 \%)$ & $40(56 \%)$ & $58(67 \%)$ & \\
\hline Good & $38(24 \%)$ & $18(26 \%)$ & $20(23 \%)$ & \\
\hline Limited & $4(3 \%)$ & $3(4 \%)$ & $1(1 \%)$ & \\
\hline Poor & $17(10 \%)$ & $10(14 \%)$ & $7(8 \%)$ & \\
\hline
\end{tabular}


Table 3. Follow-up assessments for participants who completed both 3 month and 2 year assessments post-stroke.

\begin{tabular}{|l|l|l|l|}
\hline & $\begin{array}{l}3 \mathrm{~m} \\
(\mathrm{n}=86)\end{array}$ & $\begin{array}{l}2 \mathrm{y} \\
(\mathrm{n}=86)\end{array}$ & p-value \\
\hline PREP2 category & & & \\
\hline Excellent & $56(65 \%)$ & $60(70 \%)$ & \\
\hline Good & $20(23 \%)$ & $18(21 \%)$ & \\
\hline Limited & $2(2 \%)$ & $0(0 \%)$ & \\
\hline Poor & $8(9 \%)$ & $8(9 \%)$ & \\
\hline PREP2 category correctly predicted (\%) & $69(80 \%)$ & $69(80 \%)$ & \\
\hline PREP2 category worse than predicted (\%) & $11(13 \%)$ & $8(9 \%)$ & \\
\hline PREP2 category better than predicted (\%) & $6(7 \%)$ & $9(11 \%)$ & \\
\hline ARAT & & & \\
\hline median (range) & $54(0-57)$ & $56(0-57)$ & \\
\hline median difference $(95 \% \mathrm{Cl})$ & & $1(0.0-1.5)$ & 0.012 \\
\hline ARAT score improved $\geq 6$ points (\%) & & $9(10 \%)$ & \\
\hline ARAT score deteriorated $\geq 6$ points (\%) & & $4(5 \%)$ & \\
\hline FM-UE & & & \\
\hline median (range) & $60(7-66)$ & $62.5(4-66)$ & \\
\hline median difference (95\% Cl) & & $1.5(0.5-2.5)$ & 0.005 \\
\hline FM-UE score improved $\geq 6$ points (\%) & & $18(21 \%)$ & \\
\hline FM-UE score deteriorated $\geq 6$ points (\%) & & $8(9 \%)$ & \\
\hline Motor Activity Log & & & \\
\hline median (range) & $8.1(0-10)$ & $8.6(0-10)$ & \\
\hline median difference (95\% Cl) & & $0.1(-0.03-0.4)$ & 0.2 \\
\hline
\end{tabular}

